\title{
Molecular Analysis of the Mechanical Behavior of Plasticized Amorphous Polymers
}

\author{
R. Boughalmi 1, 2, J. Jarray 2, F. Ben Cheikh Larbi ${ }^{2}$, A. Dubault' and J.L. Halary' \\ 1 Laboratoire de physico-chimie des polymères et milieux dispersés (URM7615), \\ École supérieure de Physique et Chimie industrielles de la ville de Paris, 10, rue Vauquelin, 75231 Paris Cedex 05 - France \\ 2 Laboratoire de physico-chimie des matériaux polymères, Institut préparatoire aux études scientifiques et techniques, \\ BP51, 2070 La Marsa - Tunisie \\ e-mail: rafik.boughalmi@ipest.rnu.tn - jlidi.jarray@ipest.rnu.tn - fadhel.bencheikhlarbi@yahoo.fr \\ andre.dubault@wanadoo.fr - jean-lovis.halary@espci.fr
}

Résumé - Analyse moléculaire du comportement mécanique de polymères plastifiés - Les effets de la plastification sur le comportement mécanique ont été étudiés sur deux familles de matériaux à base de poly(méthacrylate de méthyle) (PMMA) et de poly(chlorure de vinyle) (PVC). Le PMMA a été mélangé avec du poly(fluorure de vinylidène) (PVDF) dans des proportions massiques en PVDF variant de 0 à $40 \%$, compositions pour lesquelles ces échantillons sont totalement amorphes. Le di-octylphtalate (DOP) a été mécaniquement dispersé dans le PVC dans des proportions massiques en DOP variant de 0 à $20 \%$.

Le comportement en relaxation des échantillons a été étudié par analyse thermique différentielle avec une rampe de température de $10^{\circ} \mathrm{C} \cdot \mathrm{min}^{-1}$ et par analyse dynamique mécanique à une fréquence de $1 \mathrm{~Hz}$ sur une plage de température allant de $-100^{\circ} \mathrm{C}$ jusqu'à $150^{\circ} \mathrm{C}$. Les courbes contrainte - déformation ont été réalisées en compression à une vitesse de déformation de $2 \cdot 10^{-3} \mathrm{~s}^{-1}$. L'analyse des données a révélé le rôle déterminant des mouvements de relaxation $\beta$ dans le comportement plastique. En considérant la partie non élastique du travail fourni, une corrélation a été trouvée entre cette quantité et les mouvements de relaxation $\alpha$ et $\beta$.

\begin{abstract}
Molecular Analysis of the Mechanical Behavior of Plasticized Amorphous Polymers Plasticization effects on the mechanical behavior were investigated on two families of materials based on poly(methyl methacrylate) (PMMA) and poly(vinyl chloride) (PVC), respectively. For this purpose, $P M M A$ was blended with poly(vinylidene fluoride) $(P V D F)$ by co-precipitation from solution, all over the $P V D F$ range 0-40 wt\% where the samples remain amorphous. Di-octylphtalate (DOP) was mechanically dispersed in PVC over the DOP range 0-20 wt\%. The relaxation behavior of the samples was studied by differential scanning calorimetry at heating rate of $10^{\circ} \mathrm{C} \cdot \mathrm{min}^{-1}$ and by dynamic mechanical analysis at the frequency $1 \mathrm{~Hz}$ over the temperature range $-100^{\circ} \mathrm{C} / 150^{\circ} \mathrm{C}$. Stress strain curves were recorded during compression testing at a deformation rate of $2.10^{-3} \mathrm{~s}^{-1}$. Data analysis was carried out on the molecular scale; it permitted to highlight the influence of the $\beta$ relaxation motions on the plastic behavior. Consideration of the non elastic part of the energy to yield was clearly related to the contribution of $\alpha$ and $\beta$ motions.
\end{abstract}




\section{INTRODUCTION}

Yielding is a key mechanism in the deformation of polymeric materials, as it may control many properties of practical interest including damage and impact resistance.

Therefore, it is desirable to understand, at the molecular level, how the stress-strain behavior depends on such parameters as temperature, strain rate and chemical structure. Some pioneering articles were published with the aim of elucidating the macroscopic mechanical properties on the basis of polymer chain motions (Robertson, 1966; Bauwens, 1972). They were the starting point for further theoretical modeling (Escaig, 1978; Perez, 1992) and experiments (Lefebvre and Escaig, 1985; Schirrer, 1990). Recent studies carried out in our laboratory have provided comprehensive evidence for the relations existing between the yielding behavior and the character of the molecular motions involved in the main mechanical relaxation $\alpha$ and in the sub- $T g$ secondary relaxations $(\beta, \gamma)$. Different families of amorphous polymers have been investigated, including poly(methyl methacrylate) and methyl methacrylate-based copolymers (Tordjeman et al., 1997; Tézé et al., 1999), semi-aromatic polyamides (Choe et al., 1999; Brulé et al., 2001), epoxyresins (Rana, 2002) and blends of polystyrene and poly(phenylene oxide) (Creton et al., 1999).

By using the same line of reasoning as above, two additional papers have been published quite recently. First, in the case of compatible amorphous blends of poly(methyl methacrylate) and poly(vinylidene fluoride), an attempt was made for the first time (Jarray et al., 2003) to interpret the results by considering the energy to yield (which represents the under-peak area of the stress-strain curve until the yield point is reached). Secondly, the effects of plasticization on the viscoelastic and plastic behavior of poly(vinyl chloride) were discussed in relation to the disappearance of the $\beta$ relaxation motions (Dubault et al., 2003). The concept of energy to yield was also used in this latter case and proved to be useful for the data interpretation.

Confrontation of these two publications allows one to realize that PMMA-PVDF amorphous blends and DOPplasticized PVC samples have many features in common. In particular, pure PVC and PMMA present a broad $\beta$ relaxation in addition to the well-defined $\alpha$ relaxation, as recalled in Figure 1. Then, PMMA and PVC are likely to develop specific interactions with PVDF and DOP, respectively. These interactions have been shown to affect the viscoelastic and yield behavior of the two series of binary mixtures in a comparable way. And finally, the profiles of energy to yield versus temperature exhibit a similar sensitivity to the amount of additive. Therefore, the aim of the present publication is to compare in more details the behavior of the PMMA-PVDF and PVC-DOP families and to put emphasis on the possible influence of the additive size, which is obviously quite different for PVDF and DOP. Furthermore, the notion of energy to yield was revisited in a more convincing way, by relating the non-elastic deformation contribution to the relaxational behavior.

\section{EXPERIMENTAL}

\subsection{Materials}

\subsubsection{PVC and Plasticized PVCs}

The poly(vinyl chloride) (PVC) used in this study was a stabilized, commercially available material, of the grade Solvic $271 \mathrm{GC}$. It is an atactic sample (ca. 55\% of syndiotactic triads),
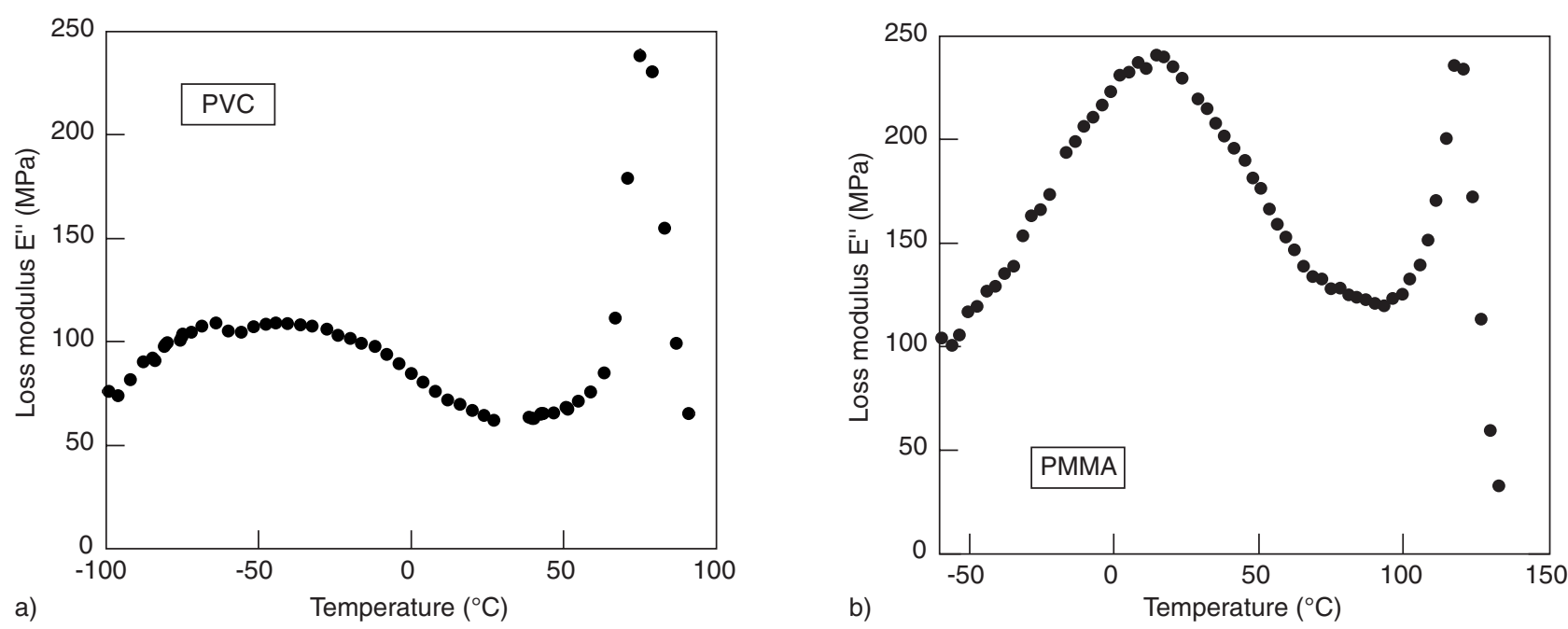

Figure 1

DMA traces of loss modulus E" (1Hz) versus temperature for the unplasticized samples: a) PVC, and b) PMMA. 
of number average molecular weight $48000 \mathrm{~g} \cdot \mathrm{mol}^{-1}$, weight average molecular weight $116000 \mathrm{~g} \cdot \mathrm{mol}^{-1}$, and viscosity index (ISO 1628-2) $128 \mathrm{ml} \cdot \mathrm{g}^{-1}$.

Plasticized PVCs, containing $m=5,10,15$ and $20 \mathrm{wt} \%$ of di(2-ethyl hexyl) phthalate (DOP), were kindly provided to us by Dr E. Gandin (Solvay, Brussels). They are coded as $m \%$ DOP. The PVC powder and the liquid plasticizer were roll-milled using an instrumented mixer Brabender PL2000-6, of maximum volume $60 \mathrm{~cm}^{3}$. Mixing was carried out at $170^{\circ} \mathrm{C}$ for $10 \mathrm{mn}$, by adjusting the speed of the roller blades to $50 \mathrm{rev} \cdot \mathrm{min}^{-1}$. Polymer and additive volume fractions were derived from the weight fractions, knowing the density of the chemicals, i.e. $1.38 \mathrm{~g} \cdot \mathrm{cm}^{-3}$ for PVC and $0.98 \mathrm{~g} \cdot \mathrm{cm}^{-3}$ for DOP.

\subsubsection{PMMA-PVDF Blends}

The PMMA used in this study was an amorphous polymer of number average molecular weight $66000 \mathrm{~g} \cdot \mathrm{mol}^{-1}$, weight average molecular weight $119000 \mathrm{~g} \cdot \mathrm{mol}^{-1}$, prepared by conventional free radical polymerization. The grade of used PVDF presented a melt viscosity of $830 \mathrm{~Pa} \cdot \mathrm{s}$ at $230^{\circ} \mathrm{C}$, a melting temperature $165-172^{\circ} \mathrm{C}$ and a maximum degree of cristallinity of about $50 \%$.

Homogeneous dilutes solutions were prepared by dissolving $5 \mathrm{wt} \%$ of polymeric materials in dimethylformamide, under continuous stirring at $50^{\circ} \mathrm{C}$ for $24 \mathrm{~h}$. Then, PVDF and PMMA were co-precipitated, by pouring the solution drop by drop into a large excess of water. Finally, the polymeric powder was dried at $100^{\circ} \mathrm{C}$ for $15 \mathrm{~h}$ in a vacuum oven. Blends prepared in this way contained $n=10,20,30$, and $40 \mathrm{wt} \%$ of PVDF. It has been checked by differential scanning calorimetry and wide-angle X-rays that all these samples are totally amorphous. These samples are coded as $n \%$ PVDF.

\subsubsection{Further Information on the Chemicals Under Study}

Chemical formulae, origin and glass transition temperature (as determined by DSC at heating rate of $10 \mathrm{~K} \cdot \mathrm{min}^{-1}$ ) of the materials presented above are grouped together in Table 1.

\subsection{Materials Evaluation}

\subsubsection{DSC Experiments}

Measurements were performed on a modulated differential scanning calorimeter (DSC) universal v3.0G, from $T A$ Instruments, by using a heating rate of $10 \mathrm{~K} \cdot \mathrm{min}^{-1}$ and a $1 \mathrm{~Hz}$ sinusoidal modulation of amplitude $1^{\circ} \mathrm{C}$. $T g$ was taken at the onset of the heat capacity jump relative to the in-phase signal.

\subsubsection{Dynamic Mechanical Analysis}

Measurements were performed on a servo-hydraulic testing system MTS 831 operated in tensile mode. The samples were subjected to a static strain of $0.1 \%$ on which a sinusoidal strain of $\pm 0.05 \%$ was superimposed. In these conditions, deformation is sufficiently small so that linear viscoelasticity conditions are fulfilled. Experiments were performed at $1 \mathrm{~Hz}$ for temperatures ranging from $-100^{\circ} \mathrm{C}$ up to temperatures higher than $\mathrm{Tg}$. The main relaxation temperature, $T_{\alpha}(1 \mathrm{~Hz})$, was defined at the maximum of the loss modulus $\mathrm{E}^{\prime}$ in the glass transition region; similarly, the secondary relaxation temperature, $T_{\beta}(1 \mathrm{~Hz})$, was defined at the maximum of the loss modulus E" in the sub- $T g$ region. The sample size was $3 \times 15 \times 40 \mathrm{~mm}^{3}$.

$m \%$ DOP samples were directly cut from the original Solvay sheets by using a diamond saw. As far as the $n \%$ PVDF samples are concerned, sheets $\left(200 \times 200 \times 3 \mathrm{~mm}^{3}\right)$ were first prepared by compression molding of the dry

TABLE 1

Pieces of information relative to the chemicals under study

\begin{tabular}{|c|c|c|c|}
\hline Chemical & Chemical formula & Origin & $T_{g}\left({ }^{\circ} \mathrm{C}\right)$ \\
\hline PVC & $-\mathrm{CH}_{2}-\mathrm{CHCl} t_{n}$ & Solvay & 74 \\
\hline DOP & $-\mathrm{COO}-\mathrm{CH}_{2}-\stackrel{\mathrm{C}_{2} \mathrm{H}_{5}}{\mathrm{CH}}-$ & Solvay & -85 \\
\hline PMMA & $\left(-\frac{\mathrm{CH}_{3}}{\mathrm{CH}_{2}-\underset{\mathrm{C}}{\mathrm{l}}-\mathrm{COOCH}_{3}}\right)^{n}$ & Arkema & 110 \\
\hline PVDF & $+\mathrm{CH}_{2}-\mathrm{CF}_{2} t_{n}$ & Arkema & -40 \\
\hline
\end{tabular}


PMMA-PVDF powder under press, at $200^{\circ} \mathrm{C}$ for $30 \mathrm{~min}$, and then samples for mechanical testing were cut from these sheets.

\subsubsection{Compression Tests}

Stress-strain measurements were performed on a servohydraulic testing system MTS 810 operated in compression mode for $\left(T-T_{\alpha}\right)$ values ranging from $-100^{\circ} \mathrm{C}$ to $-20^{\circ} \mathrm{C}$. The sample size was $3 \times 3 \times 6 \mathrm{~mm}^{3}$. The deformation rate was equal to $2.10^{-3} \mathrm{~s}^{-1}$ while the maximum strain considered was lower than 0.15. Because the levels of strain involved in the experiments are quite small, the values of nominal stress calculated by the computer were supposed, as a first approximation, to be identical to the true stresses and used instead of them without further manipulation.

\section{RESULTS AND DISCUSSION}

\subsection{Glass Transition Temperature $T_{g}$}

As already reported in previous studies (Jarray et al., 2003; Dubault et al., 2003), the monotonic decrease of $T g$ with increasing additive weight fraction follows a non linear path: curvature is turned upwards in the case of DOP (Fig. 2a), but downwards for PVDF (Fig. 2b). Several well-known equations including Gordon-Taylor or modified Fox equation yield reasonable agreement with the experimental date, thanks to the use of at least one empirical fit constant (Jarray et al., 2003). Inasmuch as specific interactions are responsible for the homogeneity of the mixture under consideration here, an alternative equation (Jenckel and Heusch, 1953) offers the advantage to bring some physical meaning. Its expression is:

$T g_{P A}=w_{A} T g_{A}+\left(1-w_{A}\right) T g_{P}+b_{A} w_{A}\left(1-w_{A}\right)\left(T g_{P}-T g_{A}\right)(1)$

As $T g_{P A}, T g_{A}$ and $T g_{P}$ are the glass transition temperature of mixture, additive and polymeric major component, respectively, and $w_{A}$ is the additive weight fraction, then $w_{A}\left(1-w_{A}\right)$ represents the probability for polymer-additive interactions and $b_{A}$ characterizes their efficiency (both their number and their strength). The best fits drawn in Figure $2 \mathrm{a}$ and $2 \mathrm{~b}$ by using Equation (1) are relative to $b_{A}=-0.67$ and +0.27 for PVC-DOP and PMMA-PVDF, respectively. The change of $b_{A}$ sign is obviously representative of the curvature change already mentioned. Negative (positive) values of $b_{A}$ just mean that component interactions are favored (disadvantaged) as compared to the linear mixing law $\left(b_{A}=0\right)$. One may tentatively suggest that the positive value of $b_{A}$ when PVDF is the additive comes from the fact that the interacting units are less likely to do so because of their connectivity within the polymer chain. However, further studies on additional systems should be required to definitely validate this idea.

\subsection{Mechanical Relaxations $\alpha$ and $\beta$}

Figures $3 \mathrm{a}$ and $3 \mathrm{~b}$ show some examples of loss modulus traces collected at the frequency $1 \mathrm{~Hz}$. In the glass transition region, the behavior of the families PVC-DOP and PMMAPVDF is quite similar. As expected from the DSC data discussed in Section 2.1, the plasticizing character of both additives shows up by a decrease of $T_{\alpha}(1 \mathrm{~Hz})$. Besides, at any composition, the values $T_{\alpha}(1 \mathrm{~Hz})$, as given in the first entry
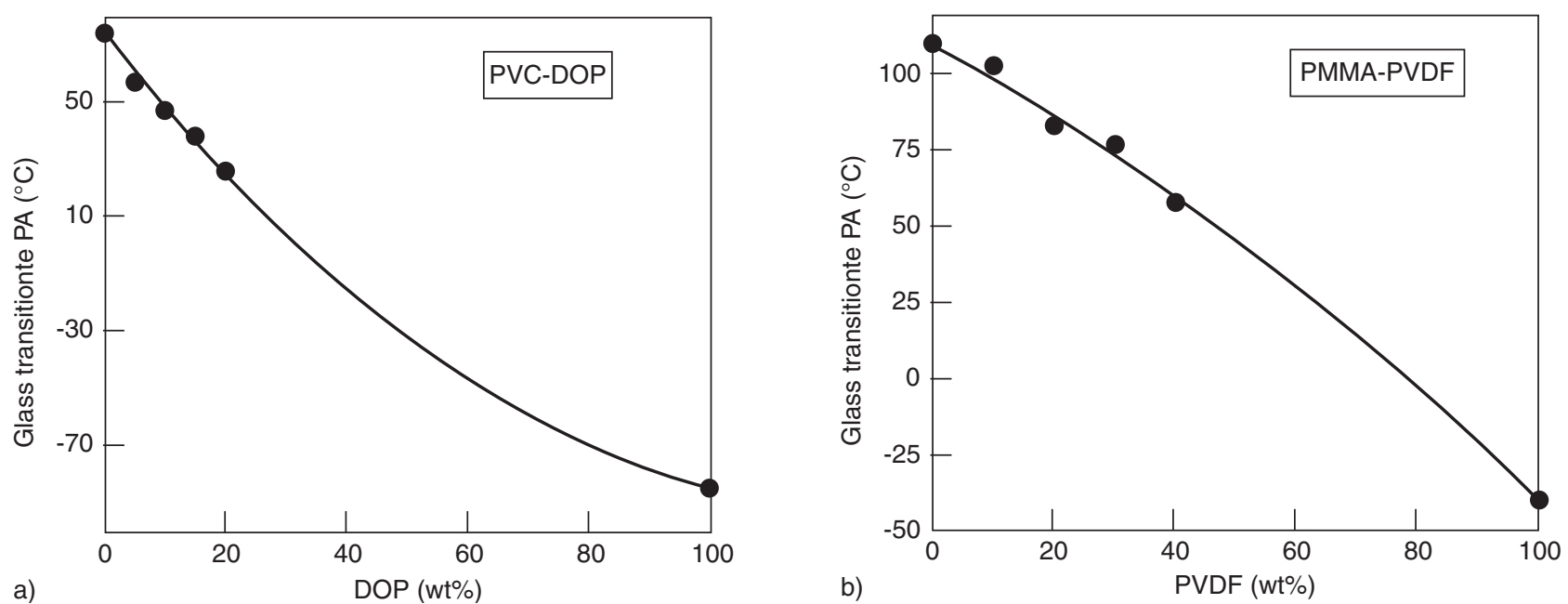

Figure 2

Glass transition temperature versus plasticizer content for: a) PVC-DOP samples, and b) PMMA-PVDF samples. The solid lines are the best fits obtained by using Equation (1). 

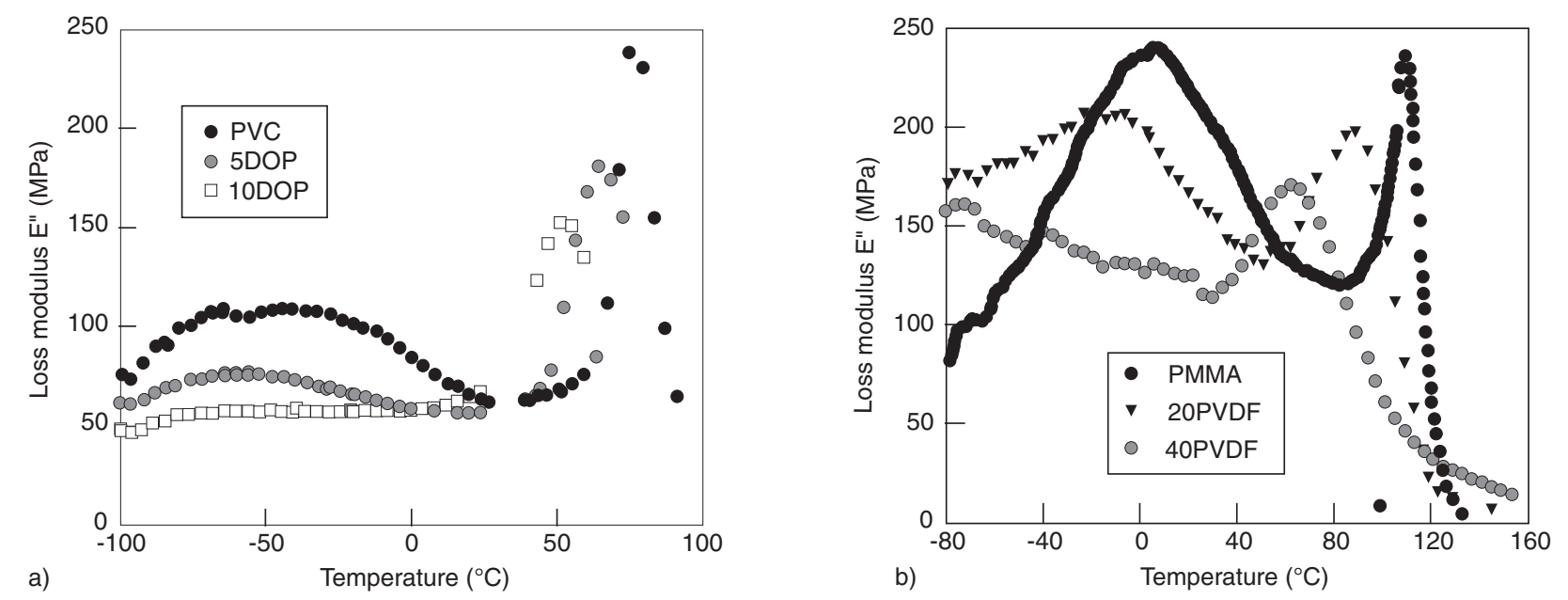

Figure 3

DMA traces of loss modulus E” (1Hz) versus temperature for some plasticized polymers: a) PVC-DOP series, and b) PMMA-PVDF series.

of Table 2, are very close to their $T g$ homolog. The DMTA traces are likely to yield some extra information regarding the distribution of interactions within the plasticized systems. As the $\alpha$ peaks continuously broaden with increasing additive amount, it turns out that the specific interactions responsible for both miscibility and plasticization are more and more distributed. In the PVC-DOP series, this observation might be justified by a lack of efficiency of the mechanical mixing at high additive amount, leading to heterogeneity effects. However, in spite of similar E" peak broadening, this argument cannot hold for the PMMA-PVDF samples whose preparation results from polymer co-precipitation, which ensures homogeneity at the molecular level.

TABLE 2

Remarkable temperatures of the different samples

\begin{tabular}{l|c|c|c|c}
\hline Sample & $T_{\alpha}(1 \mathrm{~Hz})\left({ }^{\circ} \mathrm{C}\right)$ & $T_{1}\left({ }^{\circ} \mathrm{C}\right)$ & $T_{\beta}(1 \mathrm{~Hz})\left({ }^{\circ} \mathrm{C}\right)$ & $T_{2}\left({ }^{\circ} \mathrm{C}\right)$ \\
\hline PVC & 74 & 71 & -50 & -45 \\
5DOP & 62 & 58 & -60 & -40 \\
10DOP & 50 & 54 & -60 & -55 \\
15DOP & 39 & 35 & - & none \\
20DOP & 26 & 16 & - & none \\
PMMA & 110 & 110 & 50 & 40 \\
10PVDF & 102 & 96 & 50 & 30 \\
20PVDF & 87 & 88 & - & 30 \\
30PVDF & 77 & 75 & - & none \\
40PVDF & 60 & 40 & - & none \\
\hline
\end{tabular}

Analysis of the $\beta$ relaxation region is unambiguous in the PVC-DOP family, as only the PVC units (and not the DOP

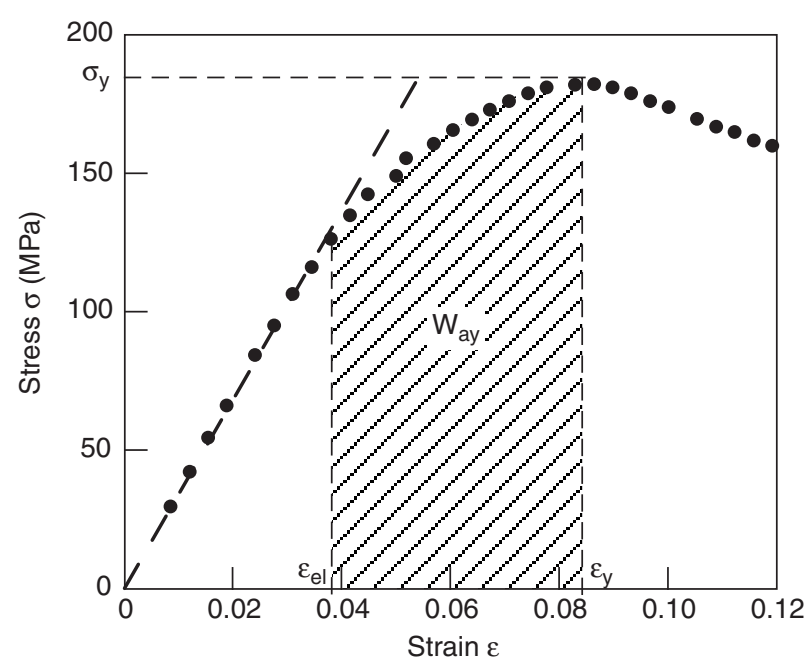

Figure 4

Sketch of the quantities of interest on a stress-compressive strain curve.

molecules) are responsible for the mechanical damping at the origin of the E" peak. As shown in Figure 3a, in the presence of DOP, the PVC $\beta$-relaxation does not change too much in position, but its amplitude is dramatically decreased. Thus, the presence of $10 \mathrm{wt} \%$ of DOP is sufficient to provoke the quasi-disappearance of the $\beta$-relaxation. It is now well accepted (Dubault et al., 2003) that such effects are the signature of antiplasticization, a phenomenon observed and discussed in various polymeric systems (Monnerie et al., 2005). In spite of its confusing name, antiplasticization means that those of the units which interact with the additive 

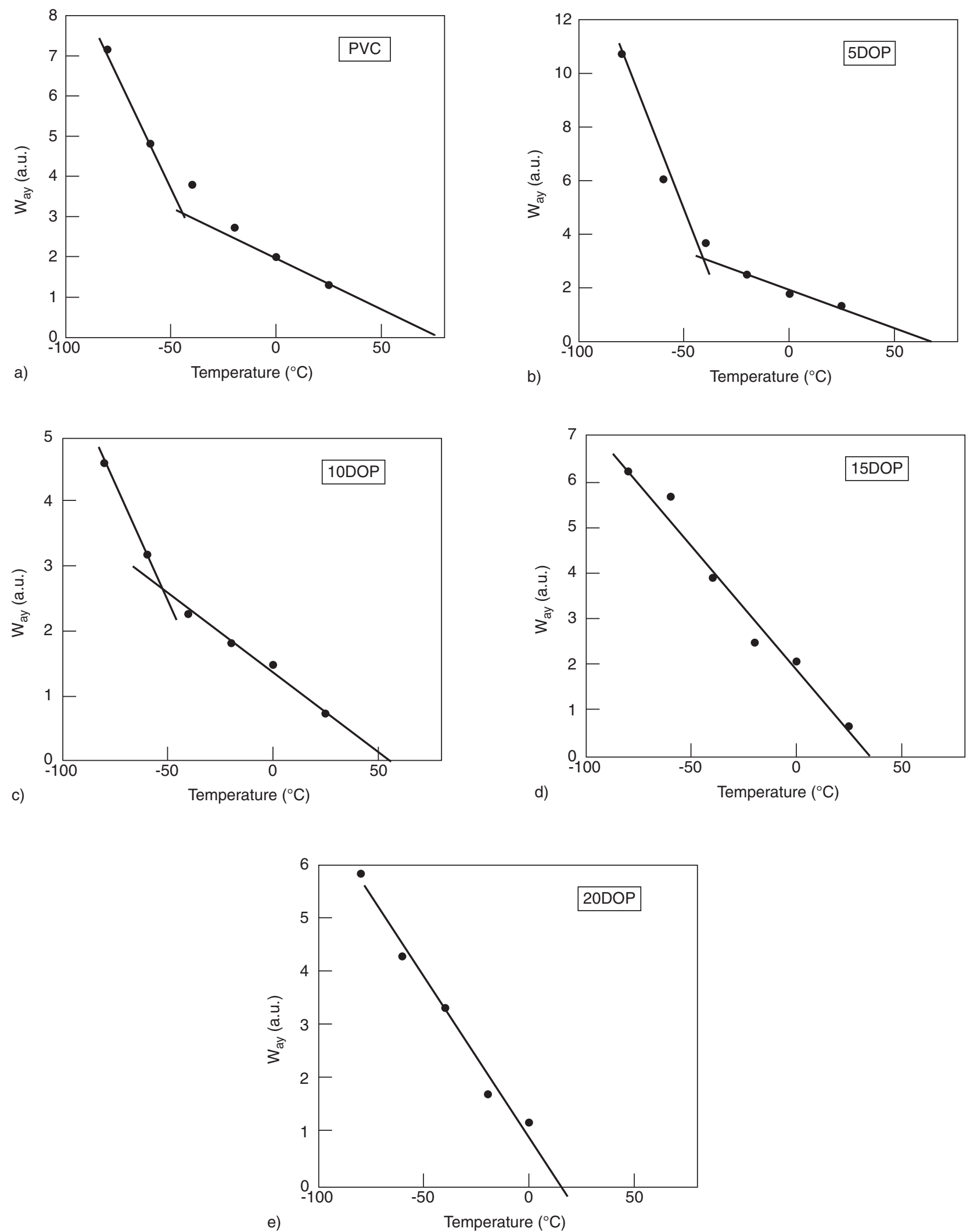

Figure 5

Temperature profiles of the anelastic energy to yield, $W_{a y}$, in pure PVC and DOP-modified PVC samples: a) PVC; b) 5DOP; c) 10DOP; d) $15 \mathrm{DOP}$ and e) $20 \mathrm{DOP}$. 
cannot undergo, at low temperature, the PVC chain torsion motions, which are at the origin of the $\beta$ process. This effect weakens at higher temperatures and vanishes at the approach of $T_{\alpha}$ because polymer-additive interactions become unlikely to resist to the brownian motion effects.

The situation is less clear in the PMMA-PVDF family, as some PVDF damping overlaps the PMMA $\beta$-relaxation peak (Fig. 3b). However, the same general trend holds regarding the decrease in E" peak amplitude with increasing additive amount. Therefore, the duality between antiplasticization of the $\beta$ relaxation and plasticization of the $\alpha$ relaxation is assumed to be valid for both PVC-DOP and PMMA-PVDF series.

\subsection{Non-Elastic Mechanical Work to Yield}

The stress-strain curves recorded in compression mode, relative to the series PVC-DOP and PMMA-PVDF (amorphous), have already been presented and discussed (Dubault et al., 2003; Jarray et al., 2003). They are not recalled here, for sake of concision. What is actually important with these curves is their general shape, schemed in Figure 4, which reveals the successive occurrence of three main deformation processes, namely: elasticity; then, anelasticity; and finally plasticity after passing the yield stress $\sigma_{y}$. On such a curve, the possible signature of molecular $\beta$ and $\alpha$ motions may be found exclusively in the anelastic and plastic deformation domains. Therefore, when the attention focuses on the mechanical events which occur before the yield point is reached, the anelastic deformation only should be considered. In other words, a pertinent quantity of interest is the anelastic energy to yield, $W_{a y}$, taken as the difference between the total mechanical energy to yield, $W_{y}$, and the elastic energy, $W_{e}$, which is just stored in the sample and restituted upon unloading (Fig. 4). To some extent, this idea to decouple the anelastic energy from the elastic energy is the same as the idea previously retained (Brûlé et al., 2001) to define the so-called index of non-elastic behavior, $I$ :

$$
I=100 \times\left(\varepsilon_{y}-\frac{\sigma_{y}}{E}\right) / \varepsilon_{y}
$$

In the case of plasticized PVC, observation of a noticeable decrease of $I$ with increasing DOP amount up to $10 \mathrm{wt} \%$ and then of a plateau value has been interpreted (Dubault et al., 2003) by the progressive hindrance of the PVC $\beta$ motions, as the result of polymer-additive interactions.

The profiles of $W_{a y}$ versus testing temperature are given in Figures 5a to 5e for PVC and the overall set of PVC-DOP samples. Let us discuss first the pure PVC case. In the high temperature range, $W_{a y}$ diminishes quite linearly with increasing temperature and vanishes at a temperature $T_{1}$ very close to $T_{\alpha}$ (Table 2). If plastic flow, which is a spontaneous thermally-activated process, takes place at $T_{1}$, then the straight line should be representative of the $\alpha$ motions. In the low temperature range, another linear profile, with a higher slope, is observed. The two above straight lines intersect at a temperature $T_{2}$, and the value of $T_{2}$ agrees quite well with the maximum of the E" $\beta$-damping. Thus, the low-temperature straight line is likely to represent deformation processes influenced by the $\beta$ motions.

These tentative explanations are nicely supported by the results relative to the samples DOP 15 and DOP 20:

- again, $T_{1}$ values are in good agreement with the viscoelastic $T_{\alpha}$ values;

- a unique linear regime (and therefore the absence of $T_{2}$ ) shows up, as the result of the $\beta$ relaxation disappearence.

The samples DOP5 and DOP10 also confirm the above trends by showing:

- $T_{1}$ values close to the relevant $T_{\alpha}$;

$-T_{2}$ values in reasonable agreement with the temperature of E" $\beta$-damping maximum;

- Less and less marked differences in slope between the two straight lines when the amount of additive increases and that the $\beta$ relaxation weakens.

The above findings can be easily paraphrased considering PMMA and the set of PMMA-PVDF (Figs. 6a to 6e). In particular, check of the similarity between $T_{1}$ and $T_{\alpha}$ is quite in agreement with what one would expect (Table 2). Moreover, the progressive change in $W_{a y}$ temperature profile from two linear regimes to only one when the $\beta$ relaxation is roughly non-existing confirms the PVC results. However, $T_{2}$ is systematically larger than the temperature of $E$ " $\beta$-damping maximum. This result could be explained by assuming that the cooperative $\beta$ motions located in the upper part of the relaxation play a prominent role in the PMMA series. One could also suggest that this need for larger domains is related to the polymeric character of the PVDF plasticizer.

In conclusion, analysis of the $W_{a y}$ profiles is a suitable way to visualize the role of the $\alpha$ and $\beta$ relaxation motions in the deformation processes in compression.

By the way, one can understand why the consideration of $W_{y}$, as done in earlier reports instead of $W_{a y}$, yields roughly the same information. It is probably just because $W_{e}$, which is not concerned by the molecular motions, is small against $W_{a y}$ in the expression of $W_{y}$.

\section{CONCLUSIONS}

The consideration of two sets of binary mixtures, namely PVC-DOP and PMMA-PVDF, in which the major component is a thermoplastic polymer presenting a broad $\beta$ relaxation, yields almost the same message. Difference in the additive nature, either a small molecular on a polymer, has a slight influence on the mechanical behavior, which remains strongly connected, as in pure homopolymers, to the details 

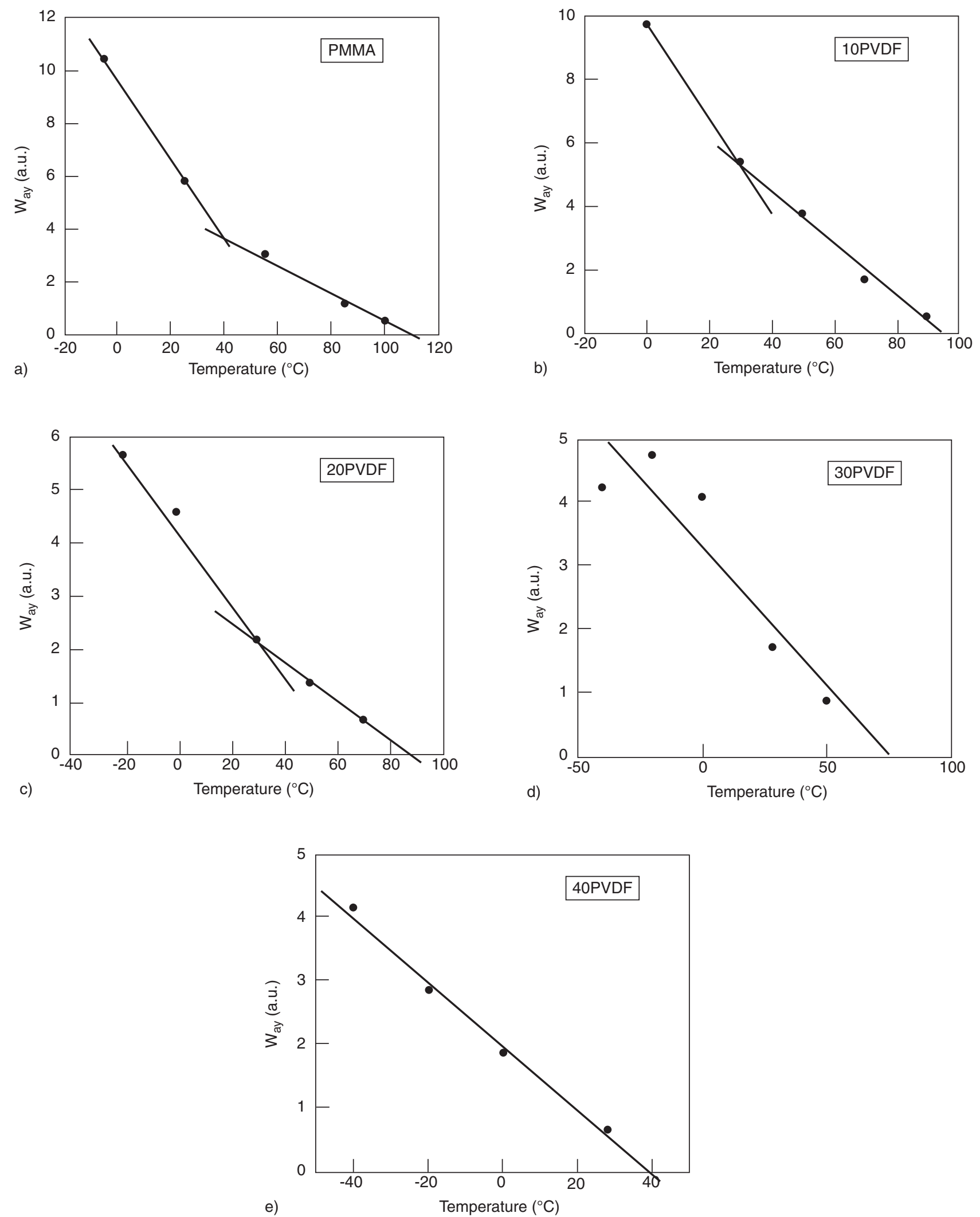

Figure 6

Temperature profiles of the anelastic energy to yield, $W_{a y}$, in pure PMMA and PVDF-PMMA blends: a) PMMA; b) 10PVDF; c) 20PVDF; (d) 30PVDF and e) 40PVDF, 
of the relaxational behavior. In particular, the signatures of the main $\alpha$ relaxation and of the secondary $\beta$ relaxation (if it exists) appear quite clearly when the temperature profiles of the anelastic energy to yield, $W_{a y}$, are considered.

\section{REFERENCES}

Robertson, R.E. (1966) Theory for the plasticity of glassy polymers. J. Chem. Phys., 44, 3950-3956.

Bauwens, J.C. (1972) Relation between the compression yield stress and the mechanical loss peak of bisphenol-A-polycarbonate in the $\beta$ transition range. J. Mater. Sci., 7, 577-584.

Escaig, B. (1978) Physics of plastic behavior of crystalline and amorphous solids. Ann. Phys.-Paris, 3, 207-220.

Perez, J. (1992) Physique et mécanique des polymères amorphes, Tec. et Doc., Lavoisier Ed., Paris.

Lefebvre, J.M. and Escaig, B. (1985) Plastic deformation of glassy amorphous polymers: influence of strain rate. J. Mater. Sci., 20, 438-448.

Schirrer, R. (1990) Optical interferometry: Running crack-tip morphologies and craze material properties. Adv. Polym. Sci., 92, 215-261.

Tordjeman, P., Tézé, L., Halary, J.L. and Monnerie, L. (1997) On the plastic and viscoelastic behavior of methylmethacrylate-based random copolymers. Polym. Eng. Sci., 37, 1621-1632.

Tézé, L., Halary, J.L., Monnerie, L. and Canova, L. (1999) The viscoelastic and plastic behaviour of methylmethacrylate-co-Nmethyl glutarimide copolymers. Polymer, 40, 971-981.
Choe, S., Brûlé, B., Bisconti, L., Halary, J.L. and Monnerie, L. (1999) On the viscoelastic and plastic behavior of semiaromatic polyamides. J. Polym. Sci. Pol. Phys., 37, 1131-1139.

Brûlé, B., Halary, J.L. and Monnerie, L. (2001) Molecular analysis of the plastic deformation of amorphous semi-aromatic polyamides. Polymer, 42, 9073-9083.

Rana, D., Sauvant, V. and Halary, J.L. (2002) Molecular analysis of yielding in pure and antiplasticized epoxy-amine thermosets. $J$. Mater. Sci., 37, 5267-5274.

Creton, C., Halary, J.L. and Monnerie, L. (1999) Plasticity of polystyrene-poly(2,6 dimethyl-1,4 phenylene oxide) blends. Polymer, 40, 199-206.

Jarray, J., Ben Cheikh Larbi, F., Vanhulle, F., Dubault, A. and Halary, J.L. (2003) Thermal and mechanical behavior of amorphous and semi-crystalline poly(vinylidene fluoride/poly(methyl methacrylate) blends. Macromol. Symp., 198, 103-116.

Dubault, A., Bokobza, L., Gandin, E. and Halary, J.L. (2003) Effects of molecular interactions on the viscoelastic and plastic behaviour of plasticized poly(vinyl chloride). Polym. Int., 52, 1108-1118.

Jenckel, E. and Heusch, R. (1953) Die Erniedrigung der Einfriertemperatur organischer Gläser durch Lösungsmittel. Kolloïd Z. Z. Polym., 130, 89-105.

Monnerie, L., Lauprêtre, F. and Halary, J.L. (2005) Investigation of solid-state transitions in linear and crosslinked amorphous polymers. Adv. Polym. Sci., 187, 35-213.

Final manuscript received in May 2006

Copyright $(\odot) 2006$ Institut français du pétrole

Permission to make digital or hard copies of part or all of this work for personal or classroom use is granted without fee provided that copies are not made or distributed for profit or commercial advantage and that copies bear this notice and the full citation on the first page. Copyrights for components of this work owned by others than IFP must be honored. Abstracting with credit is permitted. To copy otherwise, to republish, to post on servers, or to redistribute to lists, requires prior specific permission and/or a fee: Request permission from Documentation, Institut français du pétrole, fax. +33147527078 , or revueogst@ifp.fr. 